\title{
Enduring Response in Embracing Urgency in Community Care: A Critical Perspective On Social Empowerment of Bangladesh
}

\author{
Nazneen Akhter ${ }^{1}$ \\ MBBS, MPH, DLSHTM, MSC (LSE, UK), Fellow Uppsala university, Sweden, Goodenough College Uk, AHI, Japan
}

\section{Introduction \& Background:}

Bangladesh as a country could prove its development potential over the past several years with its thriving economic growth and also with a significant level of positive changes made possible in its significantly important health and social indicators including MMR, IMR, Child nutrition, fertility regulation, child survival and Infectious disease prevalence. $\mathbf{1 , 2 , 3}$ The country could make a commendable contribution in achieving Global development goal (MDG) at a significant level and also aiming to continue its effort to sustain that status quo and also making progressive changes consistently to be contributory to SDG goals and indicators towards positive development. ${ }^{2,3}$

\section{Purpose:}

This lyrical critic is an attempt to uphold the facts and evidences embedded in social development reality where the implementations are in constant challenge with urgency, need and continuity.

\section{Methodology:}

A quick and intensive desk review and web search made to capture the insights from secondary data facts, stories, evidences, news features and the findings blended with personal insights and experiences. Finally, compilation of insights and views through a laid over narrative analytics and described in a descriptive lyrical format. Purposefully ignored the figure and quantity data reflection in the write up as this write up is considered more as a social development lyric rather than a scientific write up

\section{Discussion:}

\section{Look back to our efforts and accomplishment in change process:}

In Bangladesh, with the country uplifting status of the various socio economic determining indicators and facts, of which the most significant head way towards development are the positive move on to women literacy and education, women mobility in the remote places to access health care and basic amenities, increasing number of poor women's work and economic opportunity. These are basically the important and credible year mark changes and milestone progress in women empowerment in the country. ${ }^{2,3}$ The very facts here to 
realize and recognize that the country has made a favorable drive to change most of the development indicators but when the question comes, whether we are making equal and equitable progress in achieving the indicators?? ${ }^{4,5,7}$ Surely majority of the people would echo the same way as evident in many articles and published documents that, our country is well progressing but not in an equitable manner with many of our desired indicators, especially when those are looked through a gender lens and social response point of view. Most specifically to say, these are well revealed, when it comes to gender, women empowerment, social inequality, social marginalization of the disadvantaged and poor community who remain trapped into the pocket poverty with their inherent risk and vulnerability to fight for their life \& livelihood. ${ }^{\mathbf{5 , 6 , 7}}$. They are the community people who are driven by extreme poverty, social exclusion, diverse vulnerability and are always at the brink of various risk and hardship in life and living. Be it health or social or relevant and contributory to any health status indicators, like, extreme malnourishment, prone to infectious disease including STI, victims of domestic and social violence, different catastrophic illness and many others. ${ }^{\mathbf{1 , 6 , 7 . 8}}$ In realities, these communities' real pictures are often not reflected in the social change statistics that people usually see and count on, as the general people mostly go for the surface data which are accessible to us from the service center and institutional system, also other common data sharing platforms including scientific and nonscientific category. However, while needed, selective people can access service data and statisticians can access data from the system where they belong to and there is every possibility of those data to be produced in a more customized, orchestrated form as per the need of the data audience who are the manager and decision maker of those data from policy to practice. But the community clients as beneficiaries and the people who are marginalized, unattended and have no access to information and services, their poverty picture, health and social sufferings and their deeper needs associated to their own body and mind remained unexpressed, untold, unrecognized for their lifetime. ${ }^{\mathbf{2 , 7}, \mathbf{8}}$ Their sufferings and distress remain in dark in the social development search light until there is any special purposeful deep exploratory research or need base project works are done on those areas by the development partners or any attempts made by the individual and institutional researchers from public and private settings. Through those piecemeal research and project works the unexplored and unrecognized data fortunately get revealed sometimes and also can spark the attention of national and global community. In those cases, project data/reports and fact survey findings become a high attention issue for a while or even for a longer period of time. Even in several instances when those statistics can draw readers' interest become the global high attention and priority agenda through 
different publication and scientific communication and reached to the global Public Health forum.

\section{Critical view to disjointed vs connectivity approach to interventions:}

This sort of piecemeal work of course carries a lot of value to bring the different unattended and hidden issues to be marked, surfaced and cared for! But the question here is, if the issues are looked upon and addressed in a problem and project focus approach with a given time frame, target people and a service menu to offer, this may bring result of averting risk, curing diseases and also giving acute solutions to many of their realities and vulnerabilities. But the various underneath in-depth issues are not touched upon by this way and also the dispersed poverty and social exclusion remain entrapped in this way for ages!! Very important to say, the dispersed pocket poverty, the diverse and segregated level of community marginalization and exclusion are not possible to address in this project focus, research focus disjointed approach. ${ }^{\mathbf{8 9 , 1 0}}$, Given the country scenario with its current diverse levels of vulnerability and marginalization, discrete level of pocket poverty and also different deeper level of ramified social problems, significantly visible social value distortion, it's quite challenging to overcome all these situations until there is any

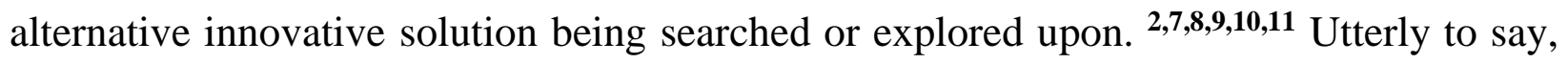
the reality here in the country, in the community there are enough serious, sincere and intense effort making attempts are in place to change these scenarios, although in various cases those are segregated, disjointed, inconsistent approach of change making.

\section{Dynamics in the quadrant of urgency, need, priority and response:}

In development field there are tons of examples as such, where we keep on looking into the needs be it observed, perceived, expressed or assessed by ourselves to invest with an aim to change-making so the people are better off than the past. Accordingly, so we keep on investing, reinvesting and happy to see the progress in quantity change, means the data is in a positive and up yielding hike comparing to baseline announcing our good efforts making a lot of sense, so the community, happy, we providers happy, our development sponsors happy too and also the District authority happy, it all ends up with a "Happy Story telling" so called Success story/evidences. This scenario sometimes gets abruptly complex and altered when the development ventures sudden way changes their target community due to a shifted urgency and importance like emerging Rohingya crisis or sometimes driven by development partners diverted attention to the new urgency and importance emerged from the community. ${ }^{12,13 .}$ Even in cases of our social development response we are thrust upon to address diversity and new needs and vulnerability to be a 
part of flagship response. So the high importance and urgent quadrant of the community people and their needs become less important and non-urgent, or a forgotten chapter of our development efforts. $\mathbf{1 3 , 1 4 , 1 5}$ The cause to realize here is, we love to deal with newness of priority which is over catchy, trendy for the societal change competition, investor friendly and also attracts most of our expected stakeholders whom we always thrive for keeping them satisfied. Guess who are those social development trendsetters?? We all know our beloved development contributors (well fit actors in PPP formatting) or the philanthropies of the society who often express their emotions in any social urgency, social needs and priorities and make response through various interventions not much realizing the continuity and far reaching impact of such urgency driven response. Its most important social development imperative to become enough thought intensive in responses whether these will only ignite to realize their need from an unrecognized level to perceived and felt level or even to an expressed level and often those are met either fully or partially for a period of time while the investors find reason to continue response and also find hundred logics around the discontinuation too! Sometimes, the philanthropist often finds their own emotion to connect with social emotion to such response to continue and be recognized by the society for their noble presence!

However, while their urgency quadrant shifts to non-urgency and non-priority, the most affected are the community who starts realizing their needs and expressing those, whether met or unmet is not the question in first hand. ${ }^{13,14,15}$ It's the fact that, at least they felt assured to have some institutional presence to listen them, respond to them and also showing efforts to address those either partly or fully, that is the assurance from the society the community need most. Although, there are several good practice and instance in community empowerment in particularly with the health and few social agenda. Here the community awareness, enlightenment, the skill enhancement, their confidence upraising, networking inside community, and the consensual agreement among the community people were made in a way that, the needs of health practice which they never been recognized/realized were surfaced to them and facilitated to learn how to cope up and get practiced to overcome their distress, poverty and health conditionalties and make the practice as part of lifestyle, existence and living. ${ }^{16,17,18,19}$ So the needs of unrecognized, which felt and expressed not any more indulged with an institutional support to address rather in bottom up way the community grown as an institution to deal those and continue to address and practice this in a sustainable way. 


\section{Idealistic approach \& evidences in community response: Empowerment Is still a far cry??}

These are the ideal example of community empowerment where the development partners dig out the community needs through situation assessment (SA) or need assessment /NA) and support to empower the community over a tangible period. In that way, they can deal with those needs with their own efforts and believe to practice the effort in their own community and individually in a lifelong manner.

There are plenty of example sets in the community of this kind specially with hygienic wash, food practice, sanitary latrine use, safe water use and also more precisely the vaccination of child and using ORS as solution to diarrhea and so on. 18, 19, 20,21 ,. As we said earlier when it comes to health there are many such empowerments happening and those are the constant encouragement to continue our development efforts in a more sustainable way. But still to say those are the good practice even seen more dispersed and erratic in nature in the community here and there. These are also disjoined in its approaching within the community, so when the statistical picture and the social change landmark scoping are made the total picture doesn't provide very impressive change in the community empowerment as a whole rather reveals more of a patchy reflection of success scenarios. ${ }^{22,23,24 .}$

For the past decades, our multi ventures in development works are making lot of statistical change impressions which are being appreciated all the way, but it's a high time to look back to our all good and relentless efforts, whether those could really touch the community empowerment element. More precisely to say, whether the working community is empowered enough to recognize their root problems, their unmet needs and finding and organizing solutions of their own or even aware enough to seeking guidance and count on into a right institution to claim their needs, who can extend support and empower them or show them the light and headway through the empowering process. ${ }^{19,24,25,26}$

\section{Conclusion:}

Our diversified marginalized community people are of vital importance from a social inclusion and exclusion point of view, to look into this more deeply whether they are socially, epidemiologically, statistically, economic indicator wise fall into the embracing practice of our democracy and inclusion culture of addressing the marginalized. This posed our country in a very challenging situation, a dilemma in between morality vs reality, emotion vs equity, social response vs political standpoint and so on. With a long end history of community responsive and socially sensitive works within /among our generalized poor, 
poverty stricken and marginalized people group, where the sustainable and ethically driven, gender sensitive social empowerment is still a far cry! The diversity in nature always claims to add on beauty, tranquility and completeness towards the sense of Equity management, but it's very true that this diversity word has a very opposite and different connotation while it is relevant to diversity in marginalization and appears in a more critical and complex dynamics to seek solution. Therefore, the ultimate empowerment of community specially the marginalized people remain entrapped into the social development process of enduring response in embracing urgency in community care where the right response may not get right weightage into the community development priority response and also the development actors priority agenda.

Note bean: This write up is a social response lyric so purposefully no data and statistics have been used here only to refer some of the statements /quotes the Bibliography piled below are reviewed to prepare this lyrical write up.

\section{References:}

1. Bangladesh Demographic and Health Survey 1993-94. Dhaka: National Institute of Population Research and Training (NIPORT), Mitra and Associates, and Macro International Inc; 1994. http://dhsprogram.com/pubs/pdf/FR60/FR60.pdf(accessed October 2014).

2. Bangladesh Poverty Assessment: Assessing a Decade of Progress in Reducing Poverty 20002010. Washington DC:The World Bank; 2013. http://documents.worldbank.org/curated/en/2013/06/17886000/bangladesh-povertyassessmentassessing-decade-progress-reducing-poverty-2000-2010 (accessed October 2014).

3. Bangladesh health sector profile. Dhaka: World Bank, WHO, Government of Bangladesh; 2010. http://documents.worldbank.org/curated/en/2010/01/16270661/bangladesh-health-sector-profile2010 (accessed October, 2014).

4. A PRICE TOO HIGH TO BEAR: Summary of Research Findings March 2014 The Costs of Maternal Mortality to Families and Communities Family Care Intl, CD ICRW, Govt of Kenya

5. Age, Gender and Diversity Policy: Working with people and Community for Equality and Protection. UNHCR, Women 1, June 2011 Research Gate \& Academia Edu

6. Country Gender Assessment: Bangladesh. Mandaluyong City (Philippines): Asian Development Bank; 2010. http://www.adb.org/documents/country-gender-assessment-bangladesh (accessed October 2014).

7. Briar, C. 1999. "In Search Of Gender-Sensetive Concepts and Measures Of Poverty, Inequality And Wellbeing." Social Policy and Social work, Massey University. pp:7

8. Country Policy and Information Note Bangladesh: Women fearing gender based violence, Version 2.0 January 2018

9. Addressing Violence Against Women and Ensuring Women Empowerment, Ministry of Women and Children Affairs

10. Bradshaw, J. Kemp, P, Baldwin,S and Rowe, A (2004). The Drivers of Social Exclusion : A Review Of the Literature For The Social Exclusion Unit In The Breaking the Cycle Series, LONDON: SEU/ODPM 
11. N. Akhter, Nov, 2018 : Realizing Facts For Eliminating Violence Against Women: Perspective From Bangladesh, Research Gate and Academia Edu .

12. Social Impact Assessment of the Rohingya Refugee Crisis into Bangladesh Key Findings and Recommendations (6 th December 2017) UNDP and UN Women 8th December 2017

13. Anjana Rai, 2016, A Study of Impact of Time Management on Academic Performance of Students Studying in School, Volume : 5 | Issue : 6 | June 2016 ISSN - 2250-1991 | IF : 5.215 | IC Value : 77.65

14. Lewis . Richard, 2014, How Different Cultures Understand Time, Business Insider, Strategy, Jun. 1, 2014, 8:35 PM,www.businessinsider.com,(2014)

15. Mohamed meriMeri, 2018 Managing Time Work in a Culture of Inaccuracy: What Success of the Time Management Matrix? International Journal of Business and Management Invention (IJBMI) ISSN (Online): 2319 - 8028, ISSN (Print): 2319-801X www.ijbmi.org || Volume 7 Issue 5 Ver. I || May. 2018 || PP-46-50

16. Gail Cooper, March 2014 : Gender Lens on Poverty Author: Rosa Cho, Policy \& Research Analyst , 2nd Edition,

17. Violence against Women in South Asian Archives of Women s Mental Health 6(3):17384 · September 2003 with 4,957 Reads, DOI: 10.1007/s00737-003-0171-9 · Source: PubMed

18. Innovative Approaches to Maternal and Newborn Health Compendium of Case Studies (OUnited Nations Children's Fund (UNICEF), New York, 2013

19. Success factors for women's and children's health: multisector pathways to progress. Geneva: The Partnership for Maternal, Newborn \& Child Health; 2014. http://www.who.int/pmnch/successfactors/en/(accessed 1 June 2014).

20 . Kuruvilla S, Schweitzer J, Bishai D, Chowdhury S, Caramani D, Frost L. et al. 2014, Success factors for reducing maternal and child mortality. Bulletin of the World Health Organization. 2014;92(7):533-544. http://dx.doi.org/10.2471/BLT.14.138131

21. Rasheda Khan Afroza Khanom, et.al 2016, Menstrual Regulation: A Decision Tainted with Stigma, Pain, and Suffering An anthropological study. Report Govt BD, DFID, Icddrb, Nirapod, Maries topes Bangladesh.

22. N. Akhter, 2015 DIVERSITY, VULNERABILITY AND YOUNG AGE: Deeper Perspective From Bangladesh, Research Gate \& Academia Edu .

23. N. Akhter, Year : 2000-2001 : An Alternative Approach To User Fee Policy In The Primary Health Care Setting Of Bangladesh. :, Bangladesh, OSF Preprint \& Research Gate

24.. Taufique Joarder, Universal Health Coverage in Bangladesh: Activities, Challenges, Recommendations and Commitments, Save The Children and BRAC

25.. The Global Gender Gap Index benchmarks national gender gaps on economic, political, education and health criteria. Source: World Economic Forum, the Global Gender Gap Report 2016.

26. Women and girls in Bangladesh Dhaka. Dhaka (Bangladesh): United Nations Children's Fund (UNICEF); 2010. http://www.unicef.org/bangladesh/Women_Girls.pdf(accessed October 2014). 